\title{
Dermatoglyphics in kidney diseases: a review
}

Buddhika T. B. Wijerathne ${ }^{1^{*}} \mathbb{D}$, Robert J. Meier ${ }^{2}$, Sujatha S. Salgado ${ }^{3}$ and Suneth B. Agampodi ${ }^{4}$

\begin{abstract}
Kidney diseases are becoming a major cause of global burden with high mortality and morbidity. The origins of most kidney diseases are known, but for some the exact aetiology is not yet understood. Dermatoglyphics is the scientific study of epidermal ridge patterns and it has been used as a non-invasive diagnostic tool to detect or predict different medical conditions that have foetal origin. However, there have been a limited number of studies that have evaluated a dermatoglyphic relationship in different kidney diseases. The aim of this review was to systematically identify, review and appraise available literature that evaluated an association of different dermatoglyphic variables with kidney diseases. This review is reported according to the Preferred Reporting Items for Systematic Reviews and MetaAnalyses checklist. The PubMed ${ }^{\circledR}$ (Medline), POPLINE, Cochrane Library and Trip Database and grey literature sources such as OpenGrey, Google Scholar, and Google were searched to earliest date to 17 April 2014. Of the 36 relevant publications, 15 were included in the review. Of these studies, there are five case reports, seven case series and three comparative studies. Possible association of dermatoglyphics with Wilms tumor (WT) had been evaluated in two comparative studies and one case series that found fewer whorls and a lower mean total ridge count (TRC). Another study evaluated adult polycystic kidney disease (APCD) type III that revealed lower TRC means in all cases. All other case series and case reports describe dermatoglyphics in various kidney disease such as acro-renal-ocular syndrome, potter syndrome, kabuki makeup syndrome, neurofaciodigitorenal syndrome, syndactyly type $\mathrm{V}$, ring chromosome 13 syndrome, trisomy 13 syndrome and sirenomelia. It is evident that whorl pattern frequency and TRC have been used widely to investigate the uncertainty related to the origin of several kidney diseases such as WT and APCD type III. However, small sample sizes, possibly methodological issues, and discrepancy in the make up between cases and control groups limits interpretation of any significant findings. Future studies with proper protocol, adequate cases, and control groups may provide stronger evidence to resolve uncertainty related to the aetiology of kidney diseases.
\end{abstract}

Keywords: Kidney disease, Dermatoglyphics, Wilms tumour, Review

\section{Background}

Kidney diseases are becoming a global burden (The Lancet 2013) with between 8 and $16 \%$ of the world's population suffering from chronic kidney disease (CKD) (Jha et al. 2013). Further, there is an increased concern of acute kidney injury as well (Lameire et al. 2013). Kidney diseases categorized as hereditary (e.g. polycystic kidney disease, Alport syndrome, etc.), congenital (malformation of urinary tract casing disease), and acquired kidney

\footnotetext{
*Correspondence: buddhikatbw@gmail.com

1 Department of Forensic Medicine, Faculty of Medicine and Allied

Sciences, Rajarata University of Sri Lanka, Saliyapura 50008, Sri Lanka

Full list of author information is available at the end of the article
}

diseases (more common) (HealthCentral). There are several identifiable causes of kidney diseases, including diabetes, hypertension, glomerulonephritis and genetically inherited diseases (Colledge et al. 2010). However, in several countries, exact aetiology of some CKD patients is unknown (Jha et al. 2013).

Dermatoglyphics is the study of the epidermal ridge patterns on the skin of the fingers, palms, toes, and soles (Cummins and Midlo 1961). Epidermal patterns start to develop during the sixth and seventh weeks of intrauterine life, and are fully formed by the end of the second trimester (Blackwell 1994). These anatomical structures have been used widely in the field of anthropology (Meier 1980) in addition to also being used

\section{Springer}

(c) 2016 Wijerathne et al. This article is distributed under the terms of the Creative Commons Attribution 4.0 International License (http://creativecommons.org/licenses/by/4.0/, which permits unrestricted use, distribution, and reproduction in any medium, provided you give appropriate credit to the original author(s) and the source, provide a link to the Creative Commons license, and indicate if changes were made. 
in medicine and genetics as a valuable diagnostic tool (Holt 1973; Reed and Opitz 1981; Shiono 1986). There is a popularity of using dermatoglyphics as a non-invasive diagnostic tool to detect and predict different medical conditions that occur in early life (Kumar and Manou 2003; Fuller 1973; Cvjeticanin et al. 2009; Pakhale et al. 2012; Gupta and Karjodkar 2013), especially in clinical settings with minimal high tech diagnostic capabilities. These studies were based on the hypothesis "if growth of the limbs is disturbed in very early fetal life changes in the epidermal ridge configurations are likely" (Schaumann and Johnson 1982; Babler 1991; Blackwell 1994). Therefore, dermatoglyphic association of various diseases with ectodermal origin have been extensively evaluated.

In addition, the relationship between different dermatoglyphic traits and the diseases of the bodily structures that originate primarily from mesoderm have been widely evaluated. The dermatoglyphics of diseases such as red cells (thalassemia, sickle cell anaemia), lymphocytes (acute lymphocytic leukaemia), cardiac muscles and vessels (ischemic heart disease, hypertension, rheumatic heart disease, and dilated cardiomyopathy) are evaluated in the literature (Annapurna et al. 1978; Sanyal 1978; Edelstein et al. 1991; Polzik and Sidorovich 1991; Palyzová et al. 1991; Oladipo et al. 2007; Dogramaci et al. 2009; Solhi et al. 2010; Bukelo et al. 2011; Ramesh et al. 2012; Fayrouz et al. 2012; Wijerathne et al. 2015).

The kidney is an anatomical structure that primarily originates from the mesoderm (Gilbert 2000; Murer et al. 2007). There are a limited number of studies that have evaluated a dermatoglyphic relationship in different kidney diseases (Curró et al. 1982; Hauser et al. 1984; Abd Allah et al. 2011). Therefore, as a start, we conducted this review to identify and appraise the different dermatoglyphic variables that might be associated with kidney diseases. These findings are an important undertaking at this time and serve as the basis for conducting this line of research.

\section{Methods}

This review is reported according to the Preferred Reporting Items for Systematic Reviews and Meta-Analyses (PRISMA) checklist (Moher et al. 2009).

\section{Search strategy}

We searched the following electronic databases earliest inclusive dates to April 17, 2014. The databases included PubMed $^{\circledR}$ (Medline), POPLINE, Cochrane Library and Trip Database. In addition, we searched the grey literature sources; namely, OpenGrey, Google Scholar, and
Google. We did not restrict the searches based on language, year of publication, or publication status.

A Boolean search strategy was constructed in Medline database using the following $\mathrm{MeSH}$ (medical subject headings) terms:

Dermatoglyphics [MeSH Terms] AND ("Kidney Diseases" [MeSH Terms] OR "Kidney Neoplasms" [MeSH Terms] OR "Kidney" [MeSH Terms] OR "Kidney/abnormalities" [MeSH Terms] OR "Kidney/embryology" [MeSH Terms] OR "Kidney Failure, Chronic" [MeSH Terms] OR "Renal Insufficiency, Chronic" [MeSH Terms] OR "Acute Kidney Injury" [MeSH Terms] OR "Kidney/ growth and development" [MeSH Terms]).

A search of other databases and grey literature was conducted with the same MeSH terms.

\section{Eligibility criteria and study selection}

Available full text articles were obtained for all studies. For articles where full texts were not available, the abstract and title were evaluated. Initially the full texts or title and abstracts were screened by BTBW based on the following inclusion and exclusion criteria.

\section{Inclusion criteria}

- Peer reviewed journal articles that describe dermatoglyphic traits in different kidney disease;

- Studies conducted on human subjects.

\section{Exclusion criteria}

- Review articles;

- Editorials.

Later all potential studies were independently reviewed by SBA and SSS for accuracy. Disagreements were discussed with a third reviewer RJM for final selection of studies to be included in the review.

\section{Data extraction}

From every included study the following details were extracted, age, sex, region, ethnicity, type of kidney disease, type of kidney abnormality and dermatoglyphic characteristics. At first, data from case reports, case series and case control studies were extracted and placed into three separate tables by BTBW. Then, these tables were checked by two other authors (SBA, SSS) for accuracy. A third author RJM finally reviewed selected studies to ensure uniformity.

\section{Results}

The literature search identified 63 articles (Fig. 1). Of these, a systematic search of PubMed databases yielded 54 studies. One study was identified through the grey 

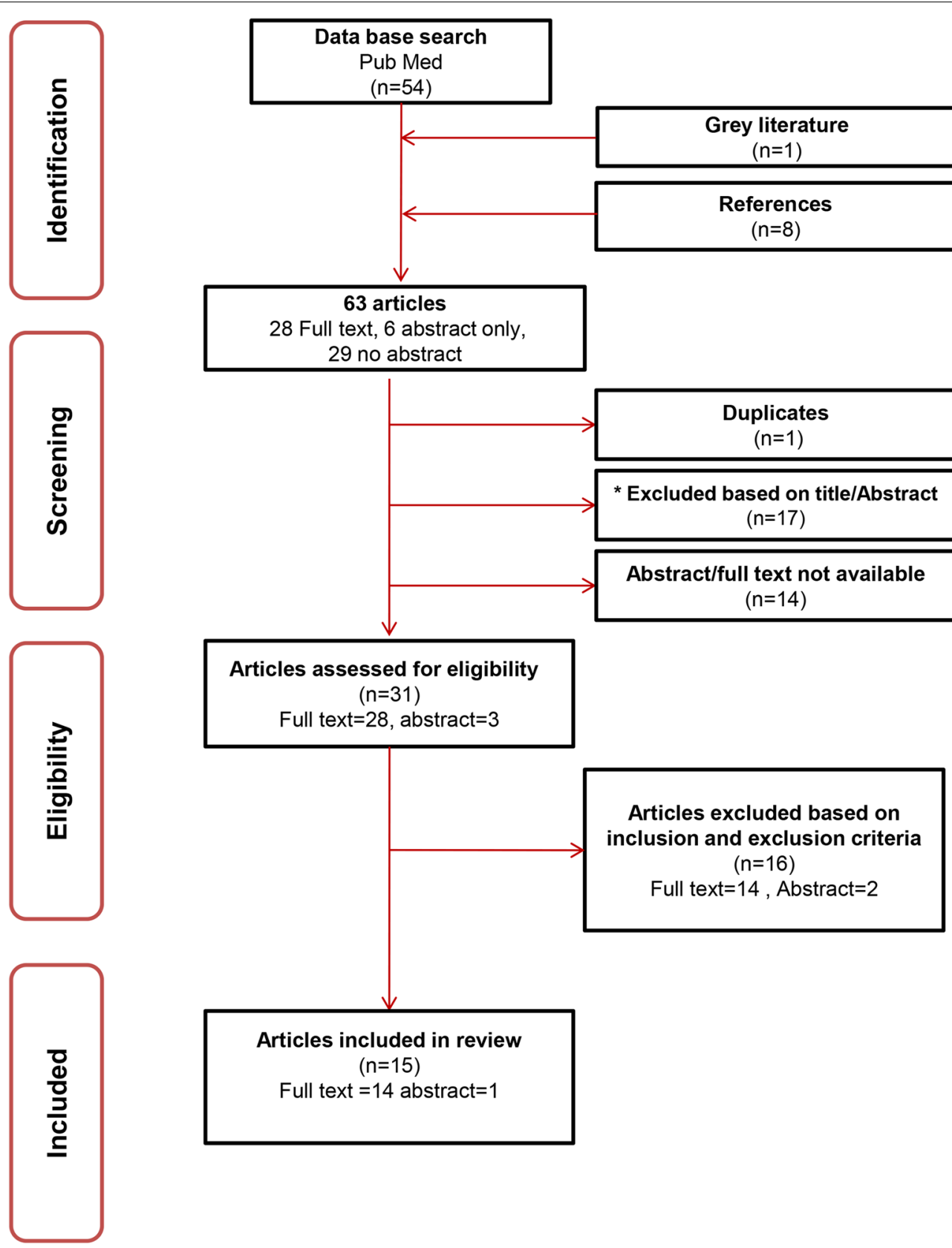

Articles assessed for eligibility

$(n=31)$

Full text $=28$, abstract $=3$

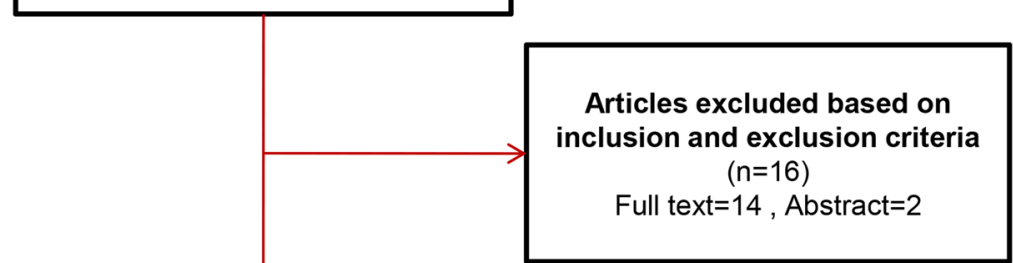

Fig. 1 Summary of evidence search and selection. Asterisk represents Online Mendelian Inheritance in Man ${ }^{\circledR}$ (http://omim.org) and Orphanet (http://www.orpha.net) database referred for disease characteristics

literature search. Eight studies were found through the manual searches of the reference lists of the retrieved full text articles.

Out of these 63 articles, 14 publications were excluded based on title or abstract (Online Mendelian Inheritance in $\mathrm{Man}^{\circledR}$ (http://omim.org) and Orphanet (http://www. orpha.net) database referred for disease characteristics), one was a duplicate and an abstract or full text was unavailable for 14 titles.

Finally, 31 articles (28 full texts, three abstracts) were assessed which led to the inclusion of 15 studies [one study is an abstract only (Hauser et al. 1984)].

Of these studies, there are five case reports, seven case series and three comparative studies. 
The extracted data are shown in Tables 1, 2 and 3, respectively.

\section{Characteristics of patients with kidney diseases}

The patient pool consisted of 28 females, 27 males and one case with male karyotype (Freire-Maia et al. 1982). In addition, there were 30 patients with Wilms tumor (Gutjahr et al. 1975) and nine patients with adult polycystic kidney disease (APCD) type III (Hauser et al. 1984) where sex of the patient was not mentioned. Age ranged from birth at 32 weeks of gestation to 45 years, for all studies that reported this information.

Cases originated from several countries: USA (Fraumeni et al. 1967; Juberg et al. 1975; Pettersen 1979; Robinow et al. 1982), Brazil (Freire-Maia et al. 1982), Canada (Halal et al. 1984), Japan (Iwama et al. 1987; Philip et al. 1992), Germany (Hoo et al. 1974), UK (Crawfurd et al. 1966; Jancar 1969), Italy (Curró et al. 1982), and for two studies the country of origin was not mentioned (Passarge 1965; Hauser et al. 1984).

Ethnicities of the cases are as follow: Brazilians (Caucasian ancestry) (Freire-Maia et al. 1982), French Canadians (Halal et al. 1984), Puerto Rican (Robinow et al. 1982), French (Philip et al. 1992), German (Philip et al. 1992). Ethnicities were not mentioned in several cases (Passarge 1965; Crawfurd et al. 1966; Fraumeni et al. 1967; Jancar 1969; Hoo et al. 1974; Juberg et al. 1975; Pettersen 1979; Curró et al. 1982; Halal et al. 1984; Hauser et al. 1984; Iwama et al. 1987).

\section{Different kidney diseases and their dermatoglyphic traits}

There were several diseases described in these studies that had stated the renal anomalies along with dermatoglyphic examinations.

\section{Wilms tumur (Fraumeni et al. 1967; Juberg et al. 1975; Curró et al. 1982)}

Wilms' tumor (WT) is the most common renal tumor in childhood and responsible for about $6 \%$ all paediatric cancers (Kalapurakal et al. 2004). The dermatoglyphic variables in WT were described in three studies (two case controls and one case series) and one case series (dermatoglyphics used to confirm monozygotic twining) that we have reviewed. The case series did not provide any comparative differences in dermatoglyphic traits and kidney diseases. The Curró et al. (1982) study, regarding digital variables, showed a significantly lower incidence of radial loops and whorls in WT patients compared to normal controls. Further, they observed significantly lower TRC (both sexes) and significantly lower pattern intensity index (PII) in male patients with WT. For palmar variables, the Cummins index (Mainline index) is significantly lower in both sexes while maximal atd angle in female patients found high in contrast to controls. Gutjahr et al. (1975) showed a lower occurrence of digital arch patterns in affected cases and a slightly higher frequency of whorls in WT patients compared to controls, yet TRC remained low, as was the ab ridge count. The palmar interdigital areas III and IV showed a low occurrence of patterns compared to controls.

Gutjahr et al. (1975) further analysed dermatoglyphics in digits of the foot, and observed an increased frequency of arches, and a reduced frequency of loops and whorls in both male and female WT patients. In addition, plantar area II showed more patterns compared to controls. Both interdigital pattern III and IV found less frequency of pattern in WT patients.

\section{Other diseases}

Our review identified several kidney diseases where dermatoglyphic features were analyzed. There are seven acro-renal-ocular syndrome cases (Halal et al. 1984), four Potter syndrome cases (Passarge 1965; Jancar 1969), four Kabuki makeup syndrome cases (Iwama et al. 1987; Philip et al. 1992), two neurofaciodigitorenal (NFDR) syndrome cases(Freire-Maia et al. 1982), a Syndactyly type V case (Robinow et al. 1982), a ring chromosome 13 syndrome case (Hoo et al. 1974), a trisomy 13 syndrome case (Pettersen 1979) and a sirenomelia case (Crawfurd et al. 1966), where different dermatoglyphic variables were described. However, these studies did not show any significant dermatoglyphic variables in patients compared to normal subjects. However, one comparative study on APCD type III patient was reported to have a lower ridge count. Unfortunately, only an abstract was available for this study. Furthermore, had the results shown that certain dermatoglyphic variables were associated with any of the above syndromic conditions, particularly those involving chromosomal aberrations (Reed and Opitz 1981), it would not have been possible to make a direct linkage exclusively between dermatoglyphics and kidney disease.

\section{Discussion}

Our review found insufficient data to support any strong dermatoglyphic relationship with kidney diseases, in general. However, two comparative studies provided weak evidence to support an association between dermatoglyphics and WT (Gutjahr et al. 1975; Curró et al. 1982) (Table 3). Could there be some reason to suspect that this association had its origin during early foetal development? On one hand, WT is an embryonic tumor of the kidney and its exact cellular genesis is yet unclear (PodeShakked and Dekel 2011). It has been hypothesized that dysregulated differentiation and abnormal postnatal retention of blastemal elements in the developing kidney 
Wijerathne et al. SpringerPlus (2016) 5:290

Page 5 of 18

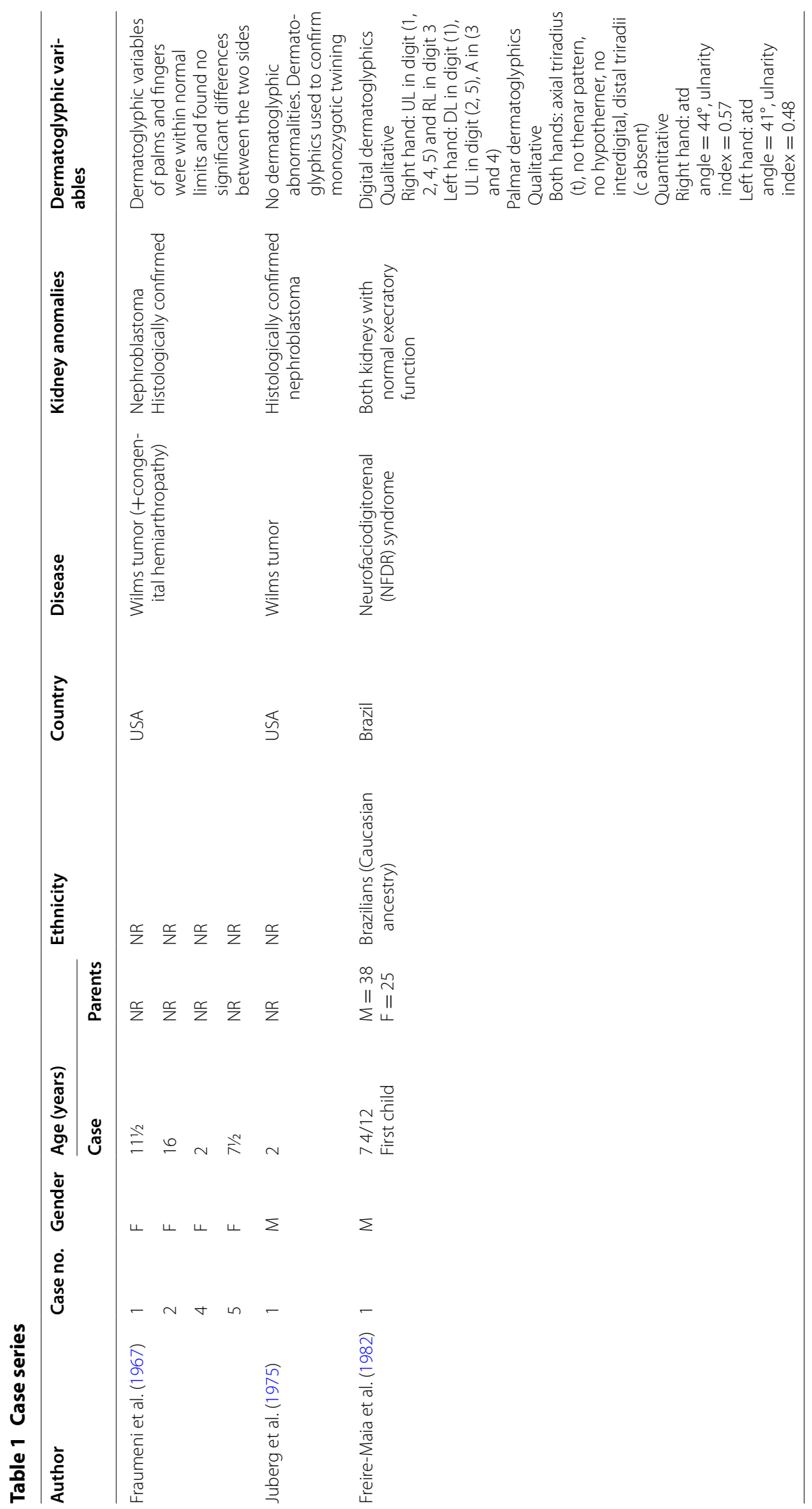




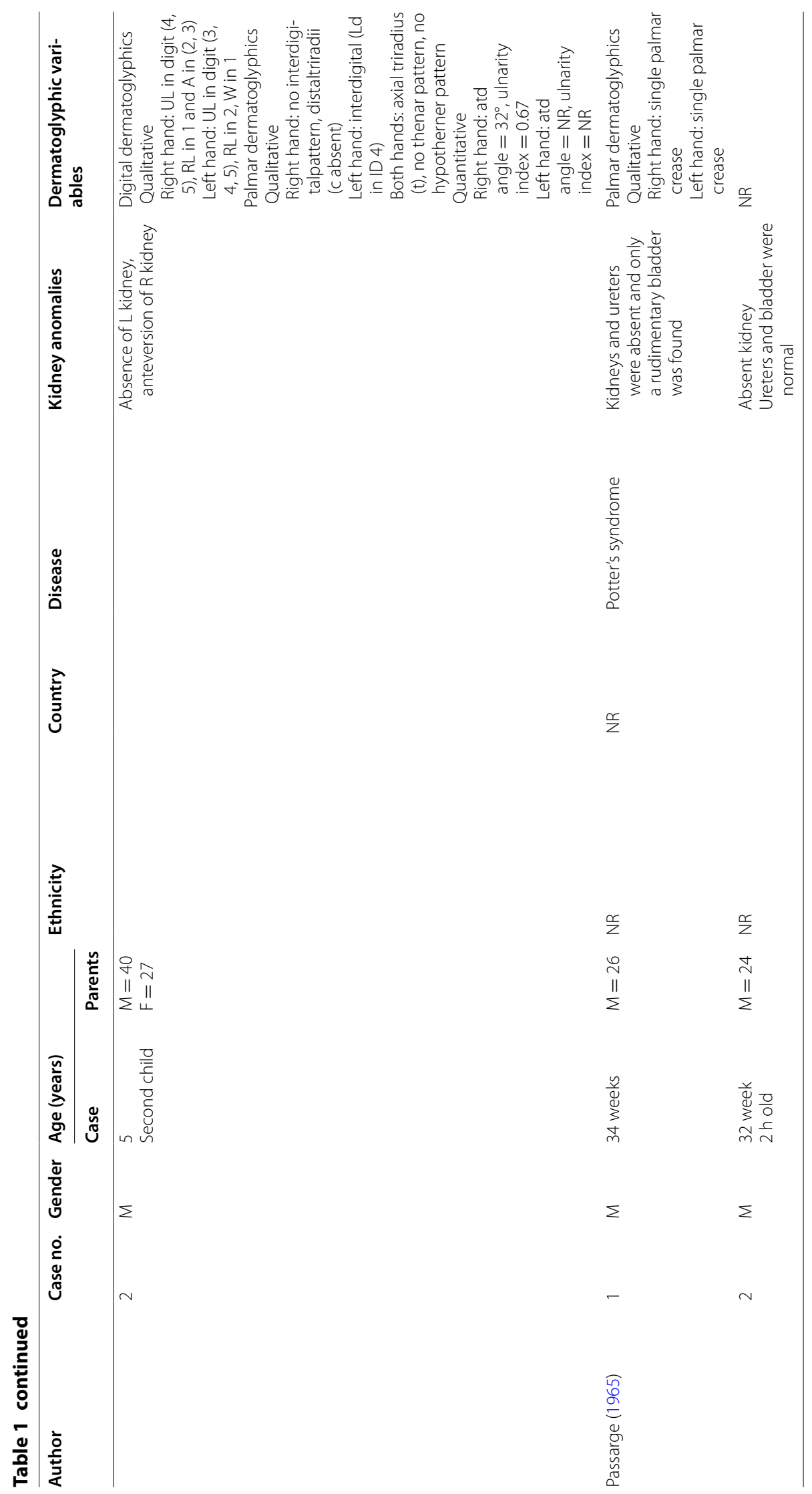




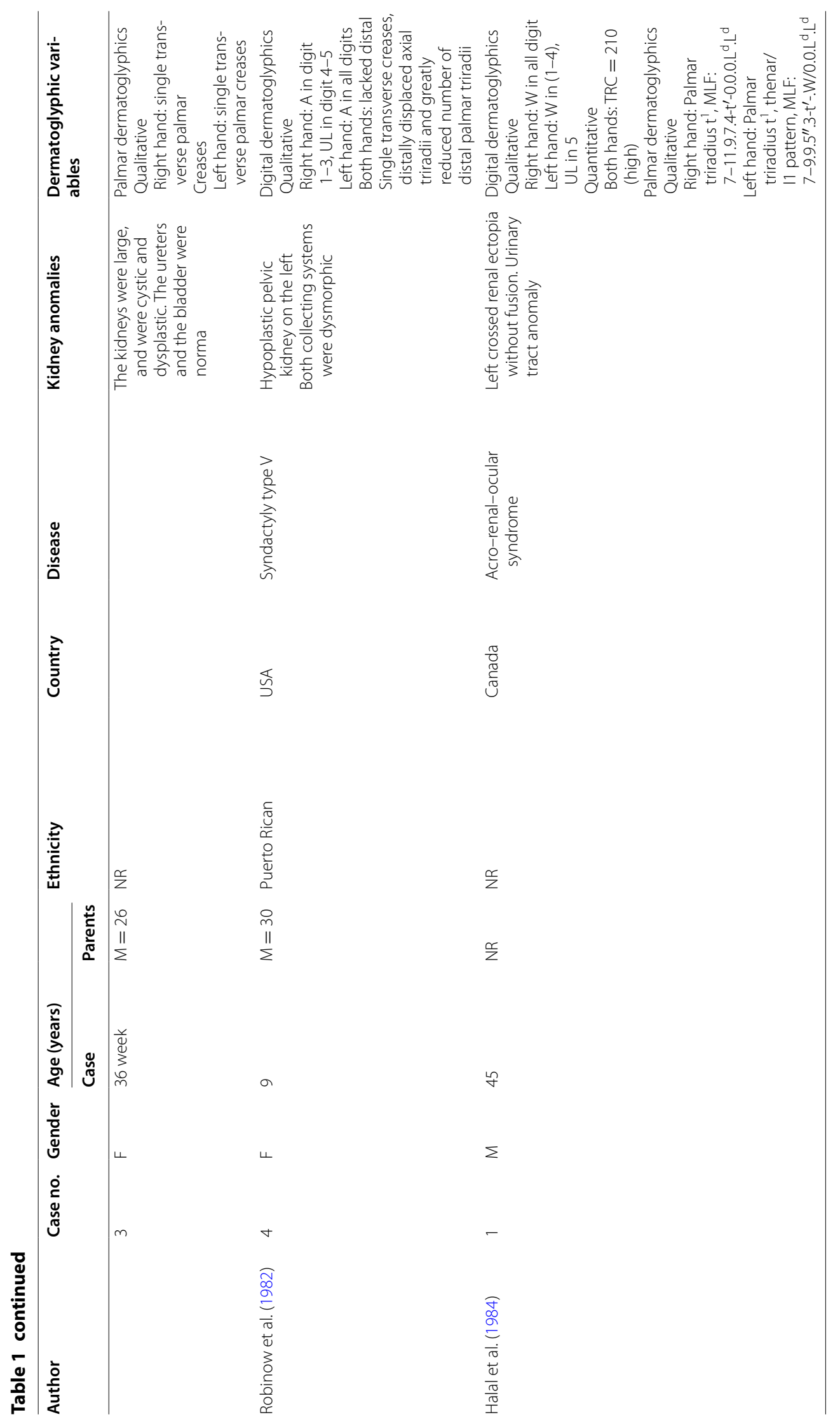




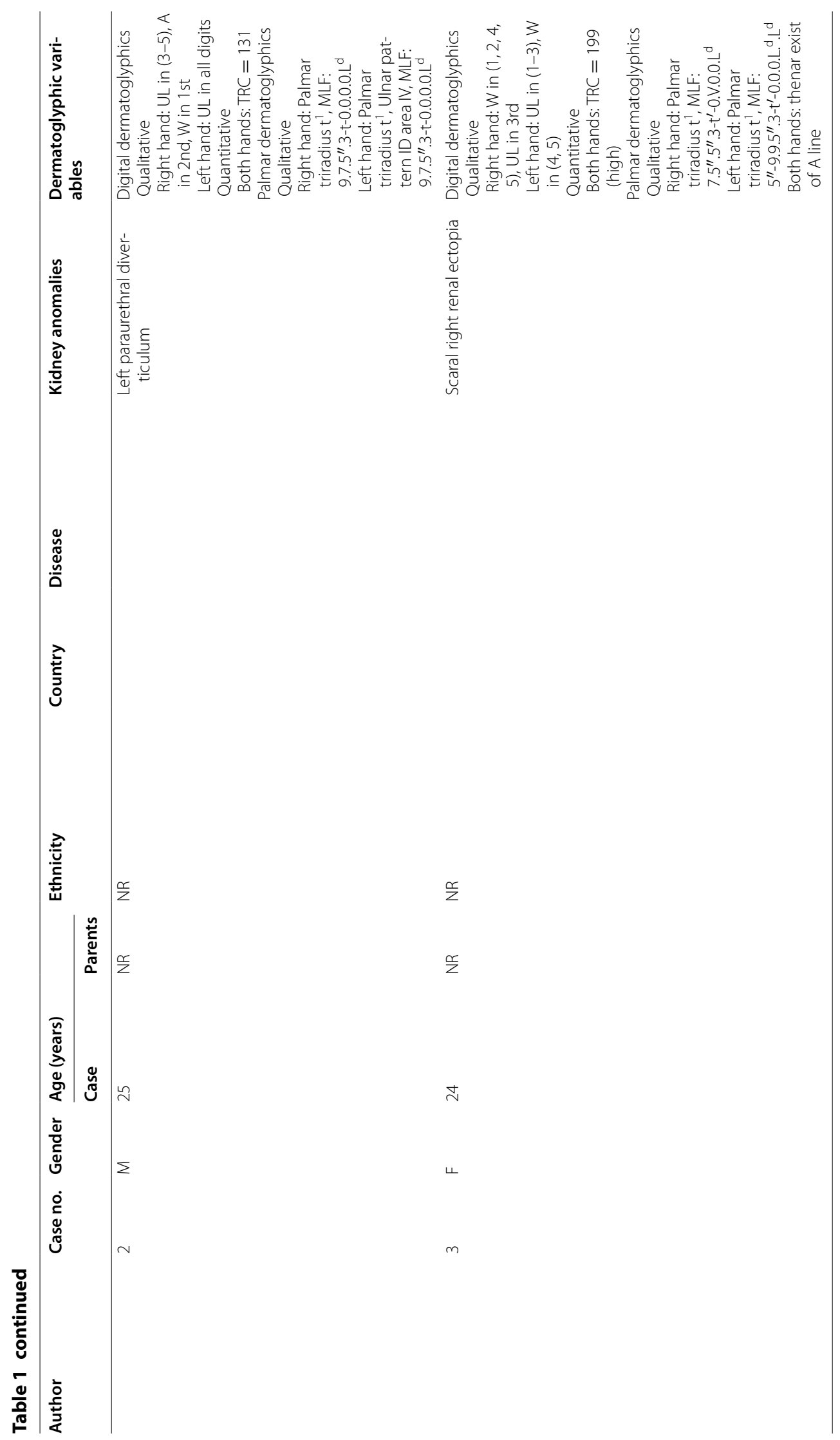




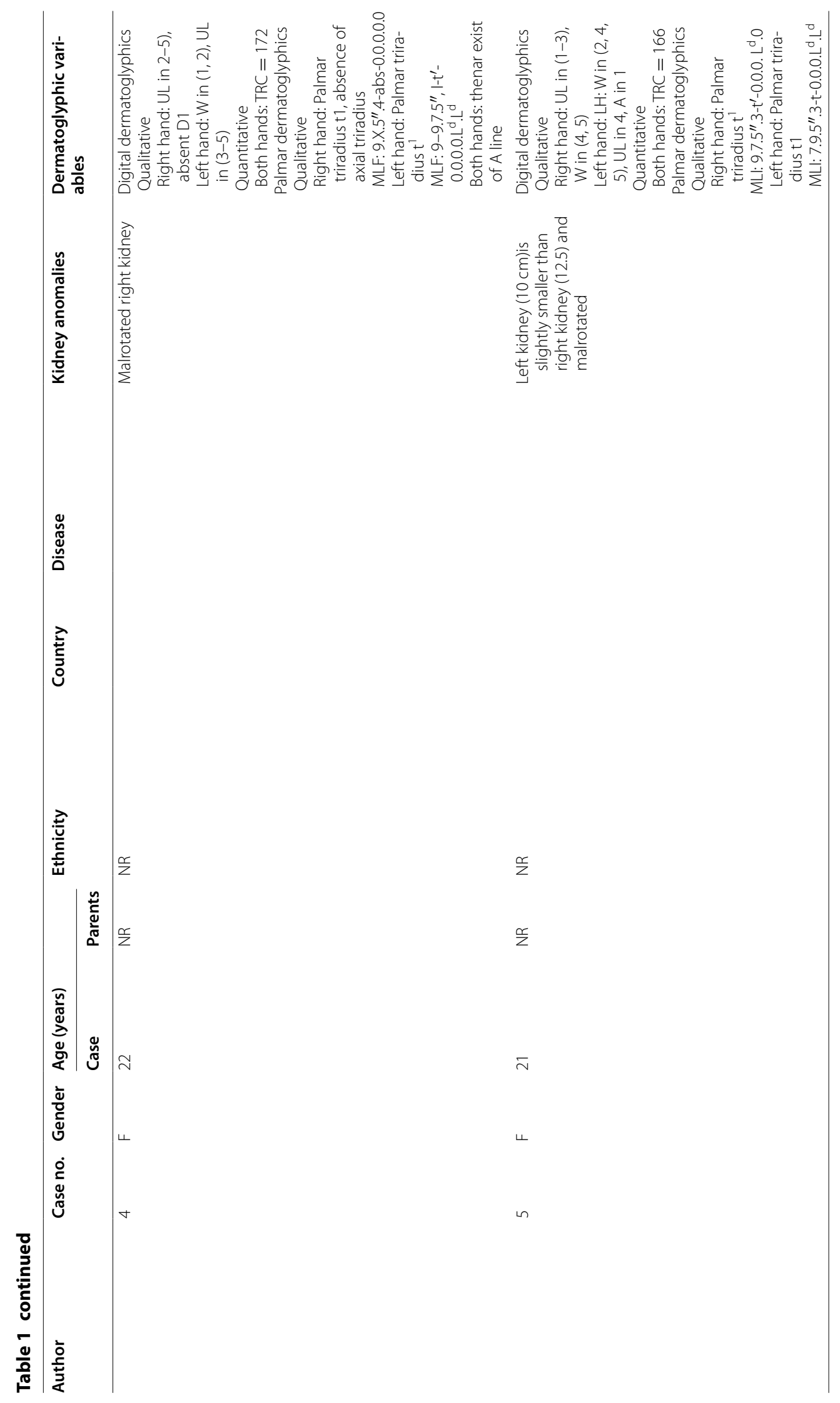




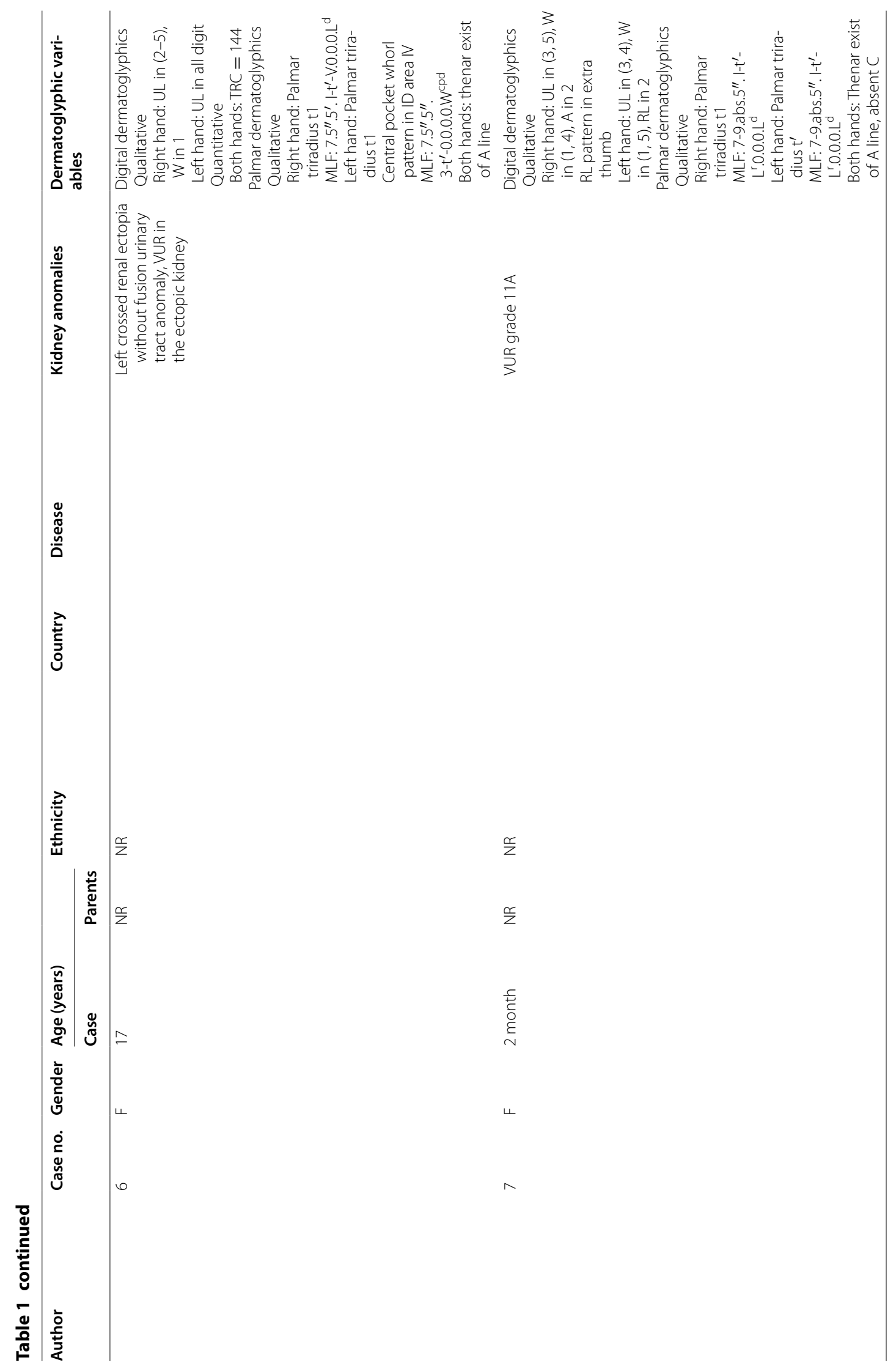




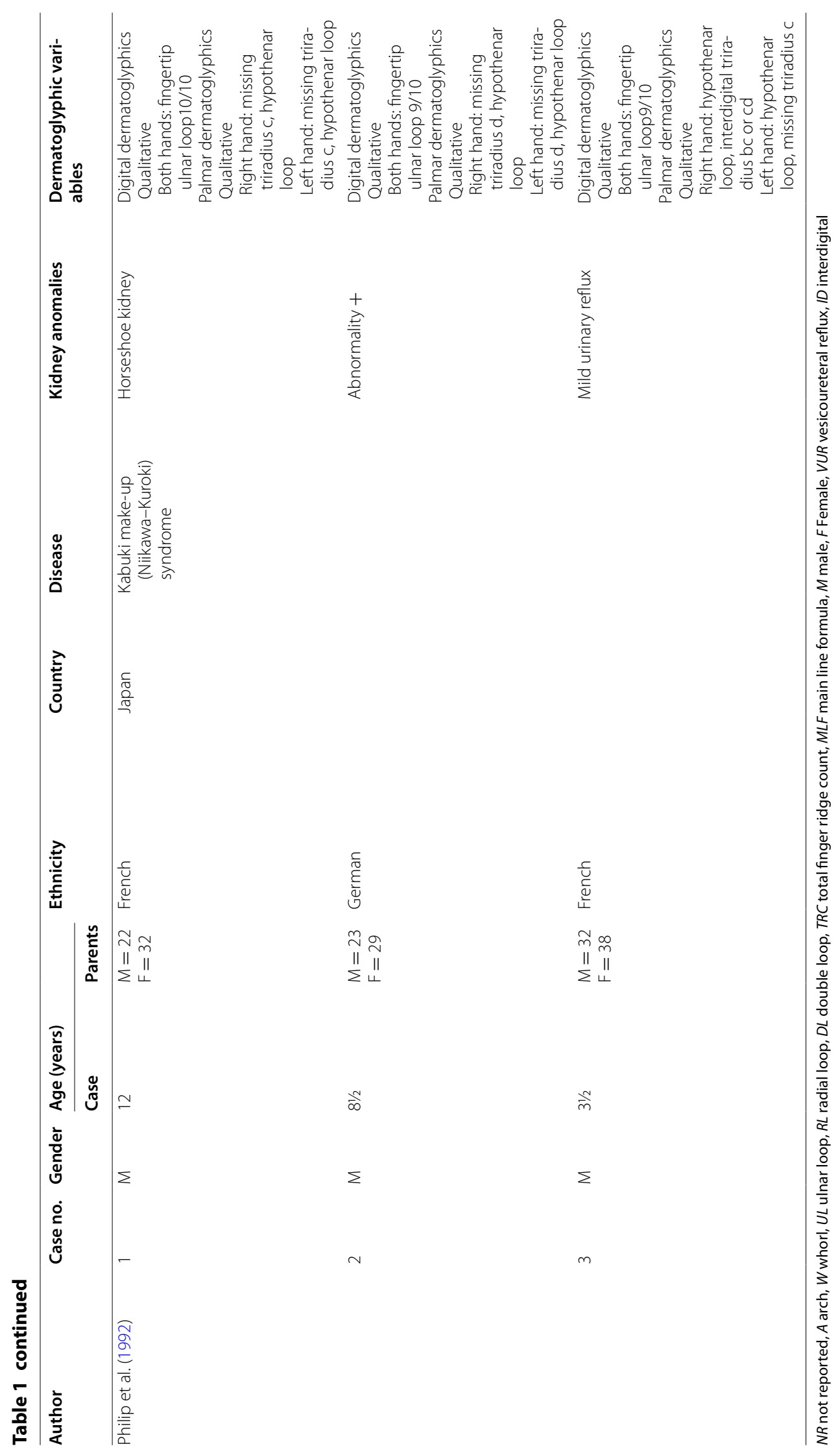




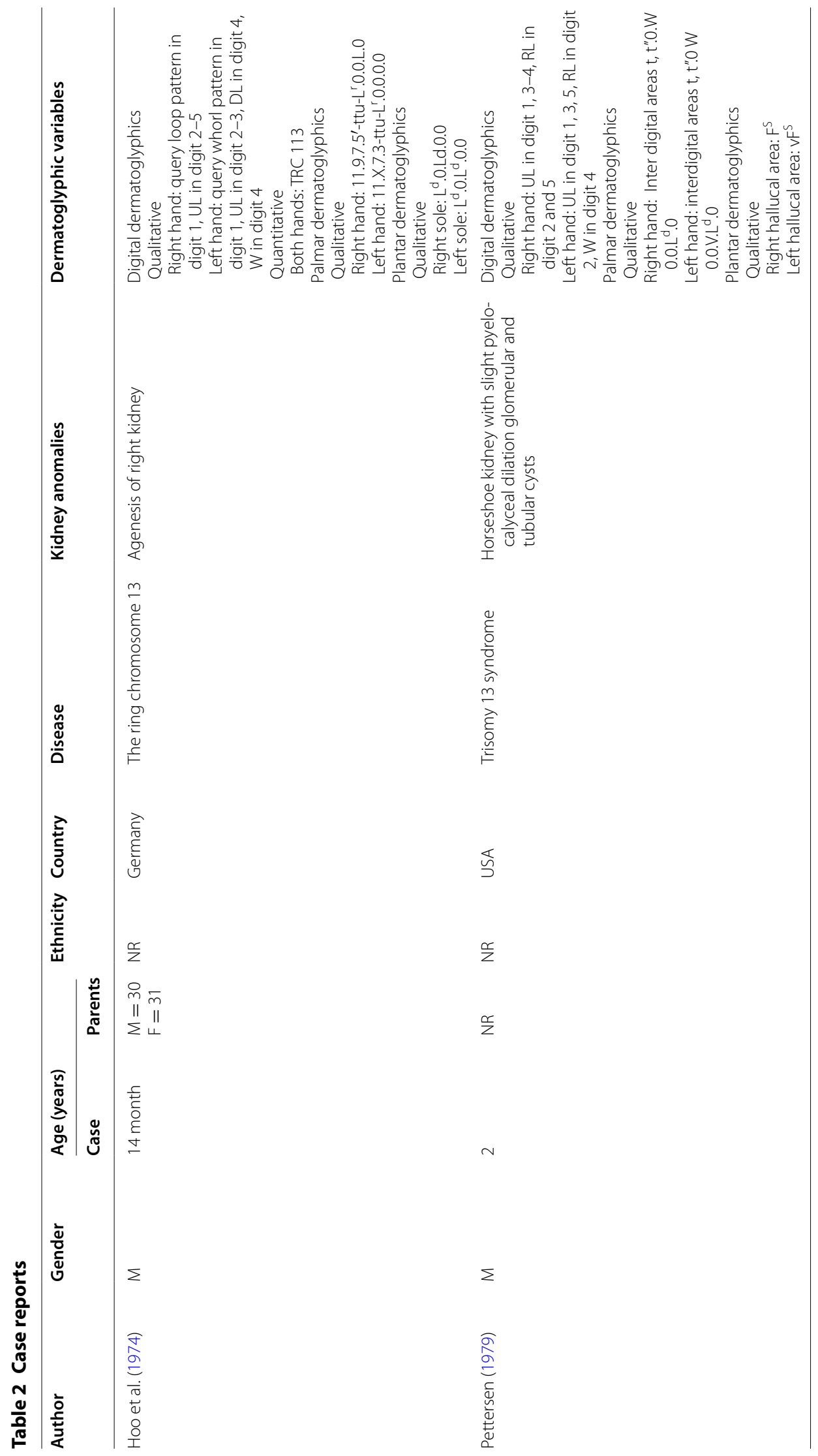




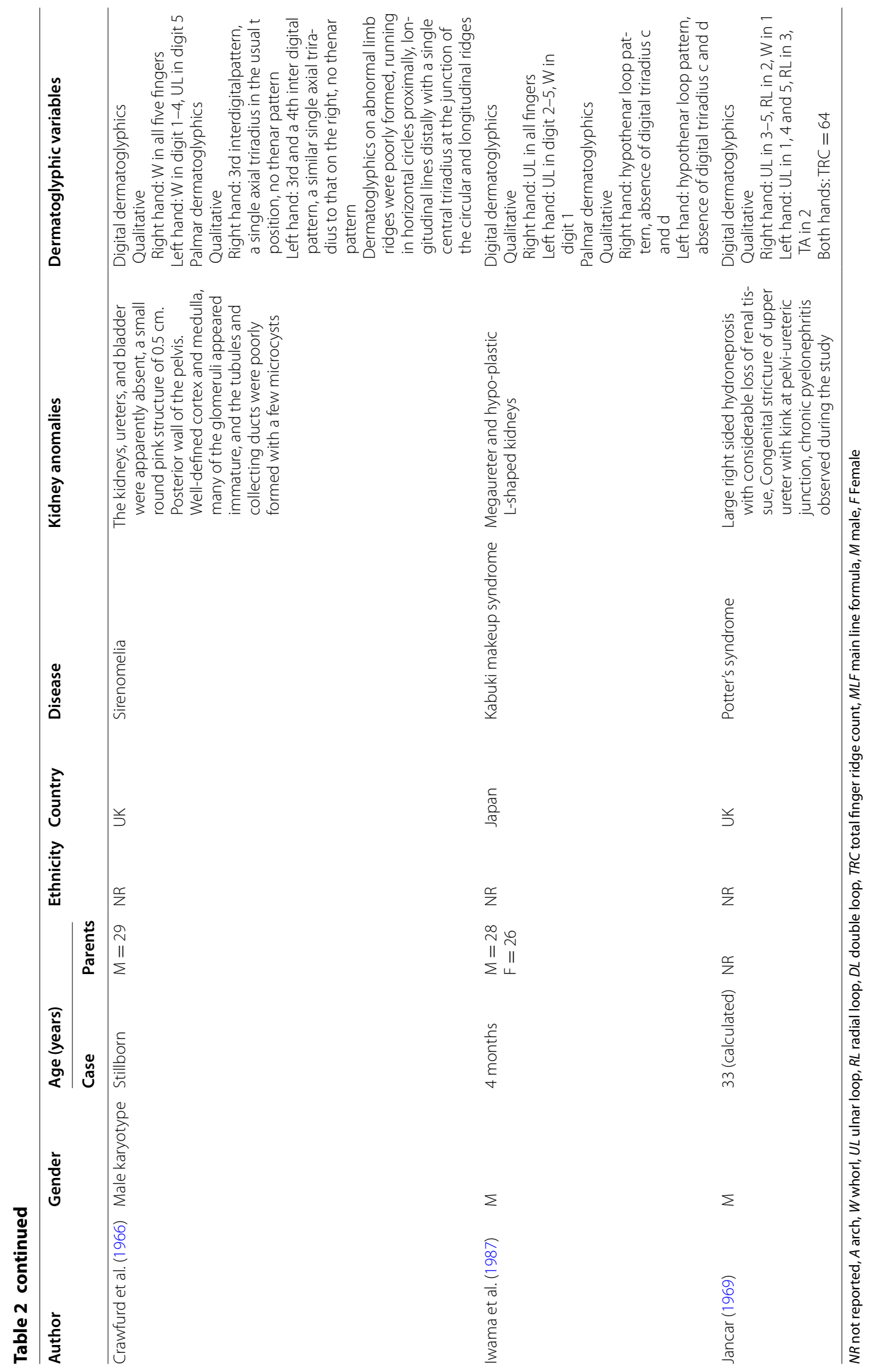




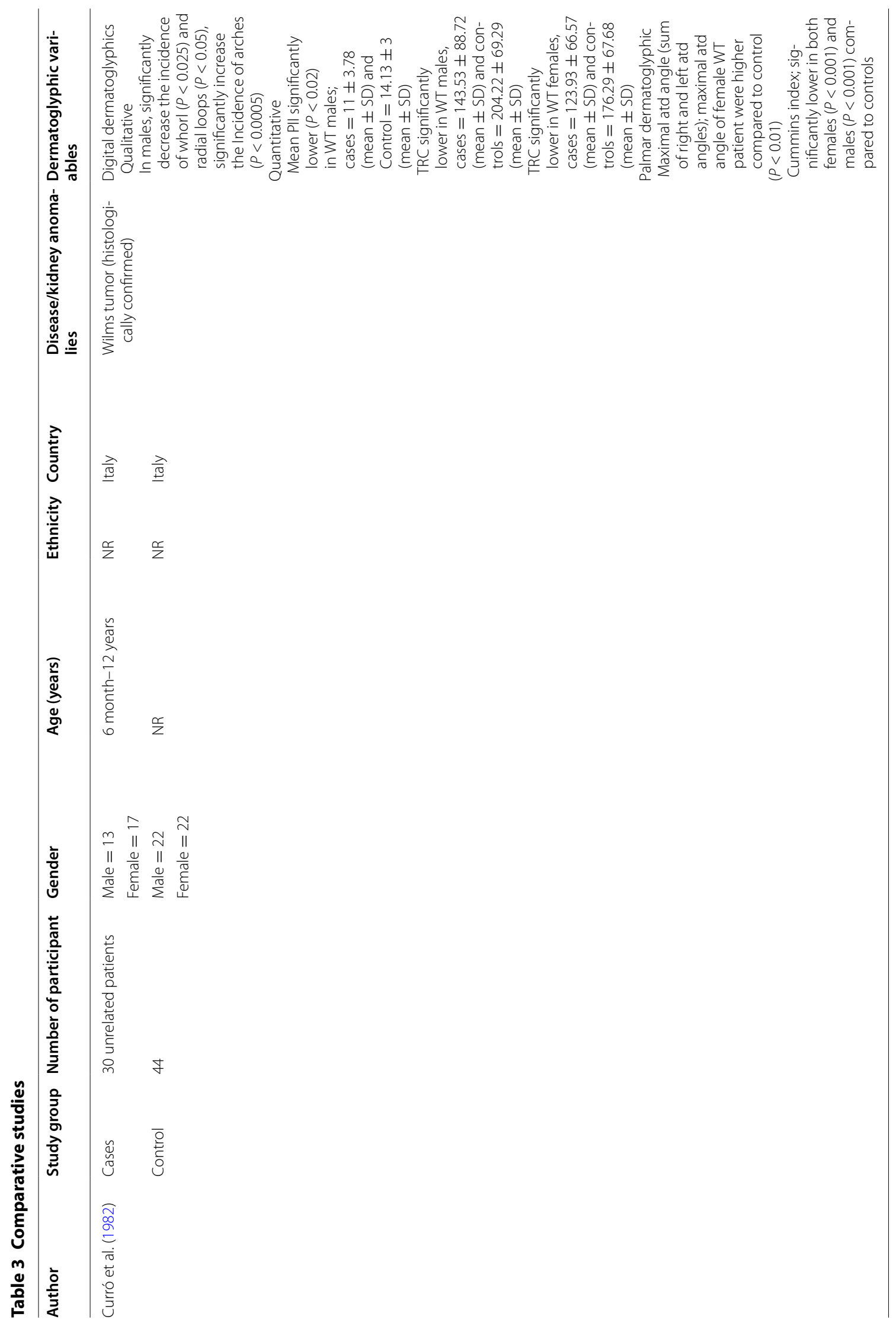




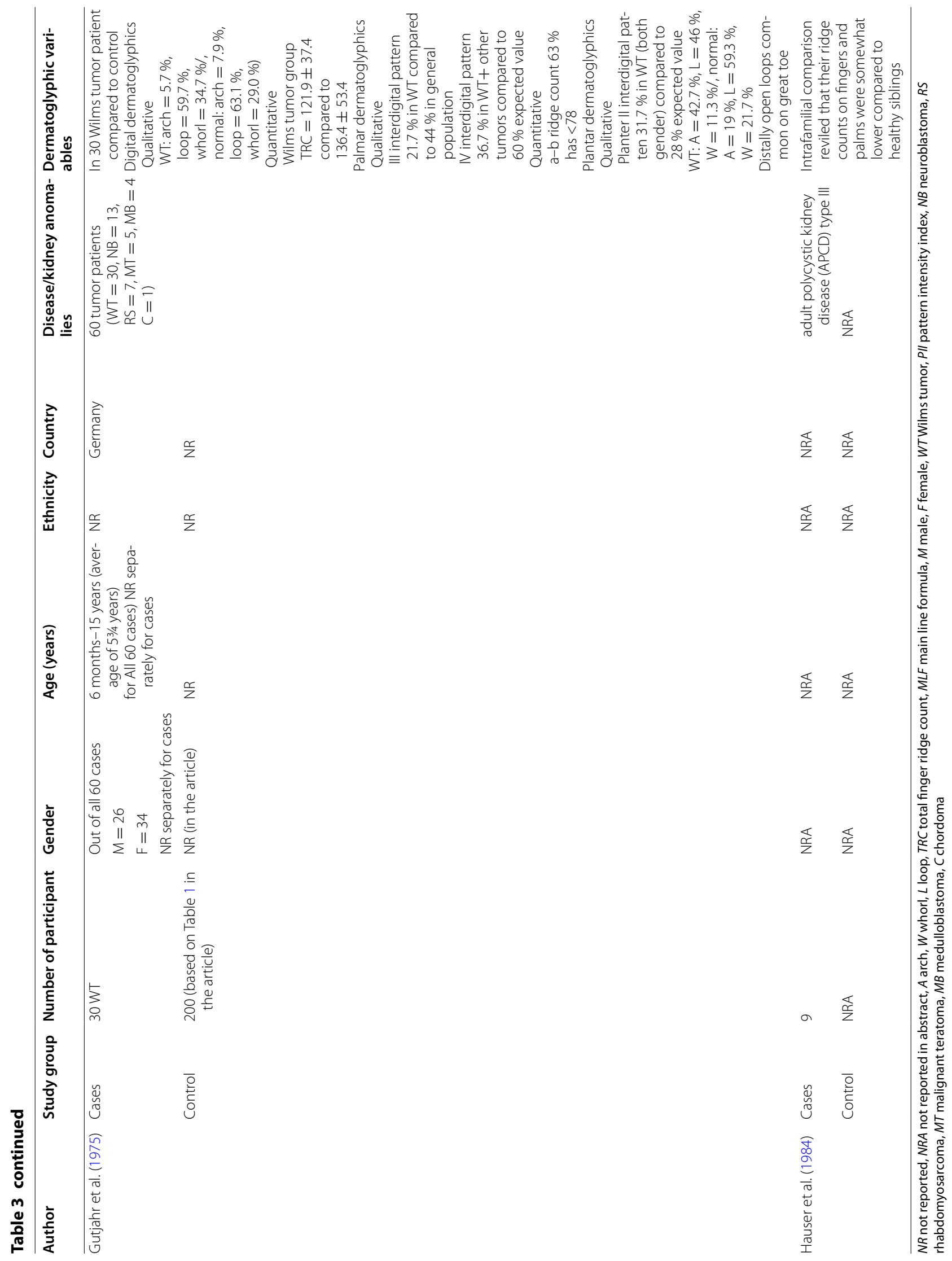


is the basis of oncogenesis of WT (Lovvorn et al. 2007). This observation was based on the presence of nephrogenic rests in many WT cases (Beckwith et al. 1990; Beckwith 1998; Lovvorn et al. 2007). On the other hand, dermatoglyphic development reflects the influence of environmental and hereditary factors during the first trimester (Okajima 1975; Babler 1991). Curró et al. (1982) and Gutjahr et al. (1975) evaluated dermatoglyphics in WT patients. They observed several dermatoglyphic traits in WT that differed from a comparison with nonaffected people, such as low TRC (Gutjahr et al. 1975; Curró et al. 1982), low ab ridge count (Gutjahr et al. 1975) and a reduced pattern occurrence in palmer III and IV areas (Gutjahr et al. 1975). Thus, it seems possible that altered dermatoglyphic and kidney development both originated at a critical time during the embryonic/fetal period.

Curró et al. (1982) observed a very low mean TRC value in both male and female WT patients, and the mean PII is likewise very low in males compared with the values found in the control sample. Inadequate sample sizes could be one reason for the unusually high mean $\mathrm{TRC}$ values $($ male $=204.22$, female $=176.29$ ), whereas TRC in the WT patients (male $=143.5$, female $=123.9)$ appears to be well within an expected range. Mean TRC value for populations generally is between 100 and 150 (Meier 1980). There seems to be no other explanation for this anomaly than that the Curró et al. (1982) study somehow ended up with a highly biased sample or there is the possibility that the authors actually utilized absolute ridge count rather than TRC.

Importantly, Gutjahr et al. (1975) observed a low TRC in WT patients compared with a control group in which sample size is adequate. This study did not report PII. In addition, they selected a control group from another study and did not report any demographic details. It should be pointed out that important dermatoglyphic variables such as TRC generally do differ between populations (Cummins and Midlo 1961; Meier 1980), so it is imperative that control samples be representative of the population source of the affected cases, for instance WT patients.

An important finding in Curró et al. (1982) is the higher frequency of arches among the WT males that would account, along with the lower proportion of whorls, for the lower mean values of TRC and PII in patients with WT. Further, these altered dermatoglyphic pattern frequencies might be evidence of delayed developmental timing because early ridge formation is associated with whorl patterns, late ridge formation with arch patterns and intermediate ridge formation with loop patterns, respectively (Babler 1991).
Hauser et al. (1984) compared dermatoglyphics of nine APCD type III patients with a control group and did not report any significant differences between patients and controls or patients and their healthy relatives. However, they observed that the intrafamilial comparison of the ridge counts in fingers and palms were fairly lower when plotted against their mid-parent values compared to their healthy sibs. We were able to retrieve only the abstract of this paper and it was not sufficient to comment on control group characteristics, although sample size appeared limited.

Several case reports and case series reports on dermatoglyphic variables were found for a range of kidney diseases such as Potter's syndrome, Kabuki makeup syndrome, sirenomelia, trisomy 13 syndrome, the ring chromosome 13, acro-renal-ocular syndrome, syndactyly type V, and NFDR syndrome. Unfortunately, these cases did not provide sufficient information to conduct a comparative analysis of dermatoglyphic variables with control samples or normal populations.

A major limitation of our review is the unavailability of full text or abstract for 14 research articles. Furthermore, PubMed database did not categorise any of these studies as case control or comparative studies under "Publication Types".

\section{Conclusion}

According to our review, it is gratifying to learn that dermatoglyphic variables such as whorl pattern frequency and TRC have been used to investigate the uncertainty related to origin of several kidney diseases, for instance, WT and APCD type III. However, inadequate sample size and/or inconsistency between cases and control groups limits interpretation of any significant findings. Nevertheless, future studies with proper protocol, adequate cases and control groups may provide stronger evidence to diminish ambiguities related to the aetiology of kidney diseases.

\section{Abbreviations}

CKD: chronic kidney disease; PRISMA: Preferred Reporting Items for Systematic Reviews and Meta-Analyses; MeSH: medical subject headings; APCD: adult polycystic kidney disease; WT: Wilms tumor; TRC: total ridge count; PIl: pattern intensity index.

\section{Authors' contributions}

BTBW conceptualized the study. BTBW, SBA, RJM and SSS designed the study. BTBW conducted the literature survey, study selection and data extraction. BTBW reviewed the articles and drafted the manuscript. RJM, SBA, BTBW and SSS edited the manuscript. SBA, RJM and SSS supervised the study. All authors read and approved the final manuscript.

\section{Author details}

${ }^{1}$ Department of Forensic Medicine, Faculty of Medicine and Allied Sciences, Rajarata University of Sri Lanka, Saliyapura 50008, Sri Lanka. ${ }^{2}$ Department of Anthropology, Indiana University, Bloomington, IN, USA. ${ }^{3}$ Department of Anatomy, Faculty of Medicine, University of Kelaniya, Ragama, Sri Lanka. 
${ }^{4}$ Department of Community Medicine, Faculty of Medicine and Allied Sciences, Rajarata University of Sri Lanka, Saliyapura, Sri Lanka.

\section{Acknowledgements}

We acknowledge the guidance provided by Dr. T.C. Agampodi and Professor Sisira Siribaddana. The authors sincerely thank to Dr. R.M.G.K. Rathnayake for her contribution during literature search. We also appreciate the help provided by Dr. Kosala Weerakoon during retrieving of articles. This study was partially funded by Rajarata University Research Grant 2013 (Grant Nos.: RJT/ RP and HDC/2013/Med. and Alli.Sci./R/02). The funding body did not have any role in the design, collection, analysis, or interpretation of the study, nor did it have any role in the decision to submit for publication. We would like to thank the anonymous reviewers for their valuable comments and suggestions to improve this manuscript.

\section{Competing interests}

The authors have no financial, personal, or professional competing interests to declare.

Received: 18 August 2015 Accepted: 12 February 2016 Published online: 08 March 2016

\section{References}

Abd Allah MAEF, Hany AM, El-Sherief IAE-B (2011) Prediction of genetically predisposed people to renal failure. Ambassad Online Mag 14. http:// ambassadors.net/archives/issue29/selected_studies.htm

Annapurna V, Ahuja YR, Reddi YR et al (1978) Dermatoglyphic studies in rheumatic heart disease. Hum Hered 28:72-78. doi:10.1159/000152934

Babler WJ (1991) Embryologic development of epidermal ridges and their configurations. Birth Defects Orig Artic Ser 27:95-112

Beckwith JB (1998) Nephrogenic rests and the pathogenesis of Wilms tumor: developmental and clinical considerations. Am J Med Genet 79:268-273

Beckwith JB, Kiviat NB, Bonadio JF (1990) Nephrogenic rests, nephroblastomatosis, and the pathogenesis of Wilms' tumor. Pediatr Pathol 10:1-36. doi:10.3109/15513819009067094

Blackwell D (1994) A dermatoglyphic investigation of selected skin disorders. Durham University, Durham

Bukelo MJ, Kanchan T, Rau ATK et al (2011) Palmar dermatoglyphics in children with acute lymphoblastic leukemia - a preliminary investigation. J Forensic Leg Med 18:115-118. doi:10.1016/j.jflm.2011.01.016

Colledge NR, Walker BR, Ralston SH (2010) Davidson's principles and practice of medicine. Elsevier, Amsterdam

Crawfurd MD, Ismail SR, Wigglesworth JS (1966) A monopodal sireniform monster with dermatoglyphic and cytogenetic studies. J Med Genet 3:212-216. doi:10.1136/jmg.3.3.212

Cummins H, Midlo C (1961) Finger prints, palms and soles: an introduction to dermatoglyphics. Dover, New York

Curró V, Mastroiacovo P, Castello M et al (1982) Palmar dermatoglyphics in Wilms'tumor. Prog Clin Biol Res 84:385-391

Cvjeticanin M, Jajić Z, Jajić I (2009) Dermatoglyphics of digitopalmar complex in forty male patients affected by rheumatoid arthritis-quantitative analysis. Reumatizam 56:25-29

Dogramaci AC, Savas N, Bagriacik MA (2009) Dermatoglyphs in patients with beta-thalassemia major and their thalassemia carrier parents. Coll Antropol 33:607-611

Edelstein J, Amylon M, Walsh JA (1991) Dermatoglyphics and acute lymphocytic leukemia in children. J Pediatr Oncol Nurs 8:30-38

Fayrouz INE, Farida N, Irshad AH (2012) Relation between fingerprints and different blood groups. J Forensic Leg Med 19:18-21. doi:10.1016/j. jflm.2011.09.004

Fraumeni JF, Geiser CF, Manning MD (1967) Wilms'tumor and congenital hemihypertrophy: report of five new cases and review of literature. Pediatrics 40:886-899

Freire-Maia N, Pinheiro M, Opitz JM (1982) The neurofaciodigitorenal (NFDR) syndrome. Am J Med Genet 11:329-336. doi:10.1002/ajmg.1320110309

Fuller IC (1973) Dermatoglyphics: a diagnostic aid? J Med Genet 10:165-169

Gilbert SF (2000) Developmental biology. Sinauer Associates, Sunderland
Gupta A, Karjodkar FR (2013) Role of dermatoglyphics as an indicator of precancerous and cancerous lesions of the oral cavity. Contemp Clin Dent 4:448-453. doi:10.4103/0976-237X.123039

Gutjahr P, Wolffram T, Emmrich P (1975) Dermatoglyphics in children with embryonic tumors. Z Kinderheilkd 120:101-110. doi:10.1007/BF00445159 (author's transl)

Halal F, Homsy M, Perreault G (1984) Acro-renal-ocular syndrome: autosomal dominant thumb hypoplasia, renal ectopia, and eye defect. Am J Med Genet 17:753-762. doi:10.1002/ajmg.1320170406

Hauser G, Maier U, MohI W (1984) Dermatoglyphics in families with Potter type III polycystic kidney degeneration. Wien Klin Wochenschr 96:801-804

Holt SB (1973) The significance of dermatoglyphics in medicine. A short survey and summary. Clin Pediatr 12:471-484. doi:10.1177/000992287301200904

HealthCentral Encyclopedia. Kidney Diseases. http://www.healthcentral.com/ encyclopedia/hc/kidney-diseases-3168920/. Accessed 9 Oct 2015

Hoo JJ, Obermann U, Cramer H (1974) The behavior of ring chromosome 13. Humangenetik 24:161-171. doi:10.1007/BF00283581

Iwama Y, Sugiyama S, Kaiga Ket al (1987) Kabuki makeup syndrome associated with megaureter. Acta Paediatr Jpn 29:182-185. doi:10.1111/j.1442200X.1987.tb00028.x

Jancar J (1969) Potter's syndrome with mental retardation (aurorenal syndrome; reno-facial dysplasia). J Ment Defic Res 13:8-12. doi:10.1111/j.1365-2788.1969.tb01061.x

Jha V, Garcia-Garcia G, Iseki K et al (2013) Chronic kidney disease: global dimension and perspectives. Lancet 382:260-272. doi:10.1016/ S0140-6736(13)60687-X

Juberg RC, St. Martin EC, Hundley JR (1975) Familial occurrence of Wilms' tumor: nephroblastoma in one of monozygous twins and in another sibling. Am J Hum Genet 27:155-164

Kalapurakal JA, Dome JS, Perlman EJ et al (2004) Management of Wilms' tumour: current practice and future goals. Lancet Oncol 5:37-46. doi:10.1016/S1470-2045(03)01322-6

Kumar A, Manou SJ (2003) Palmar dermatoglyphics as diagnostic tool: MayerRokintansky-Kuster-Hauser syndrome. Indian J Dermatol Venereol Leprol 69:95-96

Lameire NH, Bagga A, Cruz D et al (2013) Acute kidney injury: an increasing global concern. Lancet 382:170-179. doi:10.1016/S0140-6736(13)60647-9

Lovvorn HN, Westrup J, Opperman S et al (2007) CITED1 expression in Wilms' tumor and embryonic kidney. Neoplasia 9:589-600. doi:10.1593/ neo.07358

Meier RJ (1980) Anthropological dermatoglyphics: a review. Am J Phys Anthropol 23:147-178. doi:10.1002/ajpa.1330230509

Moher D, Liberati A, Tetzlaff J, Altman DG (2009) Preferred reporting items for systematic reviews and meta-analyses: the PRISMA statement. PLoS Med 6:e1000097. doi:10.1371/journal.pmed.1000097

Murer L, Benetti E, Artifoni L (2007) Embryology and genetics of primary vesico-ureteric reflux and associated renal dysplasia. Pediatr Nephrol 22:788-797. doi:10.1007/s00467-006-0390-1

Okajima M (1975) Development of dermal ridges in the fetus. J Med Genet 12:243-250. doi:10.1136/jmg.12.3.243

Oladipo GS, Olotu EJ, Fawehinmi HB, Okoh PD, Iboroma AD (2007) Dermatoglyphics in idiopathic (primary) dilated cardiomyopathy in South Southern Nigeria. Sci Res Essays 2:416-420

Pakhale SV, Borole BS, Doshi MA, More VP (2012) Study of the fingertip pattern as a tool for the identification of the dermatoglyphic trait in bronchial asthma. J Clin Diagn Res 6:1397-1400. doi:10.7860/JCDR/2012/4734.2368

Palyzová D, Kuklík M, Beránková M, Schaumann B (1991) Dermatoglyphics in juvenile hypertension. Anthropol Anz 49:361-366

Passarge E (1965) Potter's syndrome. Am J Dis Child 109:80. doi:10.1001/ archpedi.1965.02090020082010

Pettersen JC (1979) Anatomical studies of a boy trisomic for the distal portion of 13q. Am J Med Genet 4:383-400. doi:10.1002/ajmg.1320040409

Philip N, Meinecke P, David A et al (1992) Kabuki make-up (Niikawa-Kuroki) syndrome: a study of 16 non-Japanese cases. Clin Dysmorphol 1:63-77

Pode-Shakked N, Dekel B (2011) Wilms tumor-a renal stem cell malignancy? Pediatr Nephrol 26:1535-1543. doi:10.1007/s00467-011-1858-1

Polzik EV, Sidorovich SB (1991) The dermatoglyphic characteristics of patients with ischemic heart disease. TSitol Genet 25:31-35

Ramesh M, Kumari KG, Kalpana VL, Sudhakar G (2012) Palmar and digital dermatoglyphic patterns in sickle cell anemia patients of north coastal Andhra Pradesh, South India. Antrocom Online J Anthropol 8:23-32 
Reed T, Opitz JM (1981) Dermatoglyphics in medicine_problems and use in suspected chromosome abnormalities. Am J Med Genet 8:411-429. doi:10.1002/ajmg.1320080407

Robinow M, Johnson GF, Broock GJ (1982) Syndactyly type V. Am J Med Genet 11:475-482. doi:10.1002/ajmg.1320110414

Sanyal SK (1978) Dermatoglyphic alterations associated with acute rheumatic fever in children. Arch Pediatr Adolesc Med 132:692. doi:10.1001/ archpedi.1978.02120320052012

Schaumann B, Johnson SB (1982) Medical applications of dermatoglyphics. Prog Clin Biol Res 84:33-44

Shiono H (1986) Dermatoglyphics in medicine. Am J Forensic Med Patho 7:120-126
Solhi H, Hashemieh M, Nejad MLD et al (2010) Diagnostic value of fingerprint patterns: an explorative study on beta-thalassemia diagnosis. Bangladesh Med Res Counc Bull 36:27-31

The Lancet (2013) The global issue of kidney disease. Lancet 382:101. doi:10.1016/S0140-6736(13)61545-7

Wijerathne BT, Meier RJ, Agampodi TC, Agampodi SB (2015) Dermatoglyphics in hypertension: a review. J Physiol Anthropol 34:29. doi:10.1186/ s40101-015-0065-3

\section{Submit your manuscript to a SpringerOpen ${ }^{\odot}$ journal and benefit from:}

- Convenient online submission

- Rigorous peer review

- Immediate publication on acceptance

- Open access: articles freely available online

- High visibility within the field

- Retaining the copyright to your article

Submit your next manuscript at $\gg$ springeropen.com 